\title{
Prominent Uterine Leiomyoma in a Post Menopause Women- A Case Report
}

Krishna Kumar Dhakchinamoorthi ${ }^{1 *}$, Nidhi Susan Abraham $^{2}$, Shilpa Mary Saimon ${ }^{2}$, Anakha S Sachu ${ }^{2}$, Sachin Baby Thomas ${ }^{2}$, Muhammed Ramees $\mathrm{PK}^{2}$

${ }^{1}$ Professor and Head, ${ }^{2}$ Pharm.D Interns, Department of Pharmacy Practice/ Pharm.D, C.L. Baid Metha College of Pharmacy, Chennai, India

DOI: $10.36347 /$ sajp.2020.v09i11.005

| Received: 17.10.2020 | Accepted: 03.11.2020 | Published: 11.11.2020

*Corresponding author: Dr. Krishna Kumar Dhakchinamoorthi, M.Pharm., Ph.D

\section{Abstract}

Uterine fibroids are the type of benign tumors that occurs on the uterine smooth muscles also one of the most common causes and lead to hospitalization in women. Uterine fibroids developed among women during or over the age of 50 years. Many cases are asymptomatic. Pelvic examination and ultrasound can be used to diagnose the uterine fibroids. Medical therapy, surgical interventions such as hysterectomy are the treatment of choices involved in the uterine fibroids. In the present case report, a 50-year-old female patient was admitted with complaints of abdominal distension and swelling for the past two years. On physical examination, the uterus was enlarged to 36 weeks and firm inconsistency. To remove the fibroid tumor, she underwent total abdominal hysterectomy with bilateral salpingooophorectomy. The uterus mass was removed totally. It was measured around $5.5 \mathrm{~kg}$ in weight. She was further managed with post-operative care. Early diagnosis and providing alert and warning to the women who all are at risk can prevent the risk of developing uterine fibroid.

Keywords: Uterine fibroids, Leiomyoma, hysterectomy, salpingo-oophorectomy.

Copyright $\odot 2020$ The Author(s): This is an open-access article distributed under the terms of the Creative Commons Attribution 4.0 International License (CC BY-NC 4.0) which permits unrestricted use, distribution, and reproduction in any medium for non-commercial use provided the original author and source are credited.

\section{INTRODUCTION}

Uterine fibroids are the type of benign tumors that occurs on the uterine smooth muscles and are seen in extracellular levels [1], also referred as leiomyomas or myomas. Fibroids developed as a single common problem and leads to indication of surgical hysterectomy [2]. Fibroids mostly asymptomatic and remains undiagnosed in the majority of cases [3]. The symptoms of uterine fibroids are reported as abnormal uterine bleeding, dyspareunia, painful pelvic region, and obstruction on bladder or rectum, and also reported infertility [3]. The risk factors associated with uterine fibromyoma are age, nulliparity, genetic factors, early menarche, and obesity [4]. Severe anemia is one of the major complications involved in uterine fibroids that occur mainly due to excessive vaginal bleeding. The incidence of fibromyoma increases with the age up to the menopausal age and is reduced after menopause [4].

It is estimated that the rate of prevalence of uterine fibroids in reproductive women occurs in the age range of 20- 40 years, although $11-19 \%$ occur in premenopausal [5] It is also reported that one or more uterine fibroids developed among $70 \%$ of women during or over the age of 50 years. In which $30 \%$ of cases are symptomatic. Heavy and prolonged vaginal bleeding is reported in $59.8 \%$ of patients. One in thirty women who underwent hysterectomy or surgery had been affected by the major adverse event and the mortality rate may range observed between $0.4-1.1$ per thousand surgeries [4]. Hence, the complications are more with uterine fibroma. Pelvic examination and ultrasound to be performed to diagnose the uterine fibroids [6]. Medical therapy, surgical interventions, and uterine artery embolism are the treatment of choices involved in the uterine fibroids [5]. Depending upon the size, number, extend of fibroids, and patient's willingness towards fertility the surgical treatment is indicated [4].

\section{Case Report}

A 50-year-old female patient was admitted to the department of obstetrics and gynecology, in a tertiary care hospital, Chennai, India with complaints of abdominal distension and swelling for the past 2 years. It was gradually increased in a prominent size and not associated with any pain. She also had discomfort in the epigastric region for the past one week. On physical examination, the uterus was enlarged to 36 weeks and firm inconsistency. Her abdomen looked like a full-term 
pregnant woman, however, she attained menopause 5 years back. The ultrasound report of the abdomen showed mild splenomegaly, a cyst $4.7 \times 3.5 \mathrm{~cm}$ in size adjacent to the right kidney, and another one $23 \times 21$ $\mathrm{cm}$ in size located as post wall fibroid. The endometrial thickness was measured $37 \mathrm{~mm}$. The laboratory investigations were within the normal physiological parameters (Table 1).

During the preoperative evaluation period she was identified with ventricular premature contraction (VPC) and administered with T.Metoporolol XL, $12.5 \mathrm{mg}$ once daily and was switched to a dose of $25 \mathrm{mg}$ twice daily due to persistence. To remove the fibroid tumor, she underwent total abdominal hysterectomy with bilateral salpingo-oophorectomy. The uterus mass was removed totally. It was measured around $5.5 \mathrm{~kg}$ in weight.

In the post-operative period IV cefazolin was given for 5 days along with other supportive measures. On discharge, she was advised to take a soft diet with plenty of oral fluids and to maintain personal hygiene as well as wound care. She was prescribed with $T$. Acetaminophen $650 \mathrm{mg}$ twice daily and T. Ranitidine $150 \mathrm{mg}$ twice daily for 3 days with nano colloid silver ointment. Also, she was advised to continue $\mathrm{T}$. Metoprolol 25mg BD and Vitamin D 60,000 IU once a week for 8 weeks.

Table-1: Laboratory Investigation
\begin{tabular}{|l|l|l|}
\hline PARAMETERS & OBSERVED VALUE & NORMAL VALUE \\
\hline Hemoglobin & $13.7 \mathrm{~g} / \mathrm{dl}$ & $12-15.5 \mathrm{~g} / \mathrm{dl}$ \\
\hline Platelet count & $300 \times 109 / \mathrm{L}$ & $150-450 \times 109 / \mathrm{L}$ \\
\hline Packed cell volume & $39 \%$ & $37-48 \%$ \\
\hline FBS & $99 \mathrm{mmol} / \mathrm{L}$ & $<100 \mathrm{mmol} / \mathrm{L}$ \\
\hline TSH & $3.9 \mathrm{mU} / \mathrm{L}$ & $0.4-4 \mathrm{mU} / \mathrm{L}$ \\
\hline Urea & $21 \mathrm{mg} / \mathrm{dl}$ & $7-20 \mathrm{mg} / \mathrm{dl}$ \\
\hline Serum creatinine & $0.9 \mathrm{mg} / \mathrm{dl}$ & $0.6-1.2 \mathrm{mg} / \mathrm{dl}$ \\
\hline PT & $13.8 \mathrm{sec}$ & $11-13.5 \mathrm{sec}$ \\
\hline INR & 1.1 & $<1.1$ \\
\hline APTT & $33.8 \mathrm{sec}$ & $30-40 \mathrm{sec}$ \\
\hline
\end{tabular}

\section{DISCUSSION}

Uterine fibroids were reported as one of the most common causes and lead to hospitalization in women. It is under-reported in most postmenopausal women because of the absence of symptoms associated with menstruation [7]. The variation and imbalance in the stimulation of estrogen and progesterone results in the growth of fibroids. The possibility of the fibroid growth changes occurs due to the presence of a large number of estrogen and progesterone receptors in the fibroid uterine tissue $[8,9]$.

In this present case study, the associated risk factors are age and dietary habits for the development of uterine fibroids. Early menarche, pregnancy, and obesity are considered not risk factors in our patients. It was reported that the risk of uterine fibroid increases with the consumption of food additives, soya bean, red meat, chicken, not pasteurized milk and resembles the patient dietary habits. The consumption of chicken and red meat are considered as the sources of exogenous steroids [9]. However, there is no progressive evidence for the exact risk factors for the development of uterine fibroids.

On admission, the patient had a normal level of hemoglobin because of the absence of abnormal bleeding. The initial step involved in the examination of women with uterine fibroid is the pelvic examination [6]. Although the laboratory values were normal, in this case, pelvic examination along with the ultrasonography was performed to conclude uterine fibroid. The treatment choice of uterine fibroid depends on the patient age, symptoms, tumor size, and family planning status. Myomectomy, myolysis, and hysterectomy are the various surgical management options in uterine fibroids. In the present case, the patient underwent hysterectomy as she attained her menopause five years back. Further, a recent study demonstrates that the enlarged uterine fibroids and feasibility of laparoscopic hysterectomy for enlarged uterine fibroids, similarly in the present case the size of the fibroid is considered a large one [10].

Diagnosis and identification of uterine fibroids in asymptomatic women are very difficult and challenging. However, proper examination with advanced technics transvesical laparoscopy may provide greater support and be considered for the excision of leiomyomas [11]. Clinicians and health care providers should consider and apply post-operative counseling regarding the importance of maintaining hygiene and regular follow up due to the hysterectomy. Further, the management of uterine fibrosis is a challenging condition the prior diagnosis is difficult due to unexplained hormonal imbalance among postmenopausal women. Healthy dietary, habits may prevent the risk factors associated with uterine leiomyoma. 
In conclusion considering the increase in the prevalence of uterine fibroid indicates that all the women who all are above thirty years of age may undergo a routine checkup at least once a year. Through this we can prevent any uterine problems in the benign stage itself. Also, early diagnosis and management are required based on the fibroid size and desire for further pregnancy.

\section{ACKNOWLEDGEMENT}

The resident doctors, nursing staff, and technicians of Global Hospital were gratefully acknowledged.

\section{REFERENCES}

1. Simms-Stewart D, Fletcher H. Counselling patients with uterine fibroids: a review of the management and complications. Obstet Gynecol Int. 2012;2012:539365.

2. Stewart EA. Uterine fibroids. The Lancet. 2001;357(9252):293-8.

3. Zimmermann A, Bernuit D, Gerlinger C, Schaefers M, Geppert K. Prevalence, symptoms and management of uterine fibroids: an international internet-based survey of 21,746 women. BMC Womens Health. 2012;12:6.
4. Williams ARW. Uterine fibroids - what's new? F1000Research. 2017;6:2109.

5. Munusamy M, Sheelaa WG, Lakshmi V. Clinical presentation and prevalence of uterine fibroids: a 3year study in 3-decade rural South Indian women. Int J Reprod Contracept Obstet Gynecol. 2017;6(12):5596-601.

6. Fields KR, Neinstein LS. Uterine myomas in adolescents: case reports and a review of the literature. J Pediatr Adolesc Gynecol. 1996;9(4):195-8.

7. Stewart EA, Cookson CL, Gandolfo RA, SchulzeRath R. Epidemiology of uterine fibroids: a systematic review. BJOG. 2017;124(10):1501-12.

8. Rein MS, Barbieri RL, Friedman AJ. Progesterone: a critical role in the pathogenesis of uterine myomas. Am J Obstet Gynecol. 1995;172:14-8.

9. Ernest A, Mwakalebela A, Mpondo BC. Uterine leiomyoma in a 19-year-old girl: Case report and literature review. Malawi Med J. 2016;28(1):31-3.

10. Cianci S, Gueli Alletti S, Rumolo V, Rosati A, Rossitto C, Cosentino F, et al. Total laparoscopic hysterectomy for enlarged uteri: factors associated with the rate of conversion to open surgery. J Obstet Gynaecol. 2019;39(6):805-10.

11. Rey Valzacchi GM, Pavan LI, Bourguignon GA, Cortez JP, Ubertazzi EP, Saadi JM. Transvesical laparoscopy for bladder leiomyoma excision: a novel surgical technique. Int Urogynecol J. 2020. 